\title{
PERANCANGAN BISNIS MODEL BARBERSHOP BERKELANJUTAN (Studi Kasus Unick Barbershop Yogyakarta)
}

\author{
Husoen Mansovei ${ }^{1, *}$, Elisa Kusrini ${ }^{2}$, Agus Mansur ${ }^{3}$ \\ $1^{*, 2,3}$ Departement of Industrial Engineering, Faculty of Industrial Technology \\ Islamic University of Indonesian \\ KM 14.5 Jl.Kaliurang KH Mas Mansyur Building, UII Integrated Campus, \\ Phone, (0274) 895287 \\ *Email: 17916107@students.uii.ac.id
}

\begin{abstract}
ABSTRAK
Berkembangnya barbershop membuat persaingan bisnis ini menjadi semakin ketat, bahkan di Kota Yogyakarta semakin banyak bermunculan barbershop. Tujuan utama dalam penelitian ini untuk menciptakan perancangan model bisnis berkelanjutan dalam mengembangkan bisnis usaha barbershop dengan menggunakan metode SWOT, dan BMC (Business Model Canvas). Penelitian ini difokuskan untuk perancangan model bisnis baru dengan pendekatan Business Model Canvas (BMC) sembilan blok, yaitu: (1) Customer Segmentations, (2) Value Propositions, (3) Channels, (4) Customer relationship, (5) Revenue Streams, (6) Key Resources, (7) Key Activities, (8) Key Partnerships, dan (9) Cost Structure. Hasil penelitian ini menunjukkan bahwa model bisnis yang selama ini dilakukan dalam usaha Unick Barbershop Yogyakarta ditemukan kelemahan beberapa elemen BMC, oleh karena itu perlu dilakukan perbaikan pada 4 elemen yaitu; Blok Key Activities, Blok Value Propositions, Blok Customer Segmentations, dan Blok Key Resources
\end{abstract}

Kata kunci: barbershop, bisnis model kanvas, berkelanjutan

\begin{abstract}
The development of barbershop has made this business competition even tighter, even in the city of Yogyakarta there are even more barbershop growing each year. The main objective of this research is to create a design of sustainable business model in developing a barbershop business using the SWOT method and the BMC (Business Model Canvas). This research is focused on designing a new business model with a nine-block Canvas Business Model (BMC) approach, namely: (1) Customer Segmentations, (2) Value Propositions, (3) Channels, (4) Customer relationship, (5) Revenue Streams, (6) Key Resources, (7) Key Activities, (8) Key Partnerships, and (9) Cost Structure. The results of this study indicate that the business model that has been carried out in the Unick Barbershop Yogyakarta business has found weaknesses in some BMC elements, therefore it is necessary to improve on 4 elements, namely; Block Key Activities, Block Value Propositions, Block Customer Segmentations, and Block Key Resources
\end{abstract}

Keywords: barbershop, canvas business model, sustainable

\section{Pendahuluan}

Bisnis Barbershop memiliki daya tarik yang cukup besar dalam menarik jumlah pelanggan, maka tidak heran untuk memperoleh pelanggan dalam barbershop cukup mudah apalagi jika barbershop itu sendiri memiliki ciri khas dan juga barberman yang berkualitas, sekarang barbershop tampaknya menjadi tren bisnis di bidang gaya rambut pria. Menurut penelitian [1] bisnis tempat cukur khusus pria alias barbershop ternyata memberi penghasilan menjanjikan. Tak heran jika barbershop terus bertambah di Indonesia. Dengan lebih dari 5.000 brand barbershop di Indonesia saat ini, male grooming trend terus berkembang didorong oleh meningkatnya minat pria akan tatanan rambut yang lebih kekinian. [2]. Para pelaku usaha barbershop perlu mendapatkan pemahaman loyalitas pelanggan dengan persfektif yang lebih luas dan dapat diaplikasikan dengan mendesain stimulus-stimulus berkaitan dengan kepuasan pelanggan [3]. Memperbaiki kualitas pelayanan pelanggan barbershop dengan tujuan untuk membuat mereka lebih puas dan loyal dalam rangka mencapai tujuan

barbershop [4]. Masalah keberlanjutan perusahaan mengharuskan untuk mengubah model bisnis, jika ingin mempertahankan keunggulan kompetitif. Keberlanjutan jangka panjang dari suatu organisasi bisnis harus diukur dengan keberlanjutan ekonomi, 
tanggung jawab sosial, perilaku etis, dan inisiatif lingkungan [5]. Oleh karena itu tujuan utama dalam penelitian ini untuk menciptakan perancangan model bisnis berkelanjutan dalam mengembangkan bisnis usaha barbershop dengan menggunakan metode, SWOT, dan BMC (Business Model Canvas).

\section{Metode Penelitian}

Konstruksi berfikir dalam penelitian ini sebagai berikut:

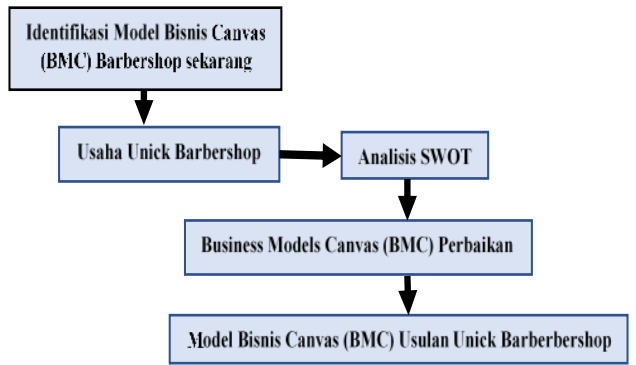

\section{Analisis SWOT Model Bisnis Sekarang}

Proses selanjutnya setelah melakukan perumusan proses bisnis yang sedang berjalan yaitu mengevaluasi model bisnis dengan menggunakan metode analisis SWOT. Analisis ini diterapkan dalam sembilan blok Bisnis Model Canvas (BMC) dengan item-item yang disarankan oleh [6]. Berikut ini akan menerangkan penilaian-penilain SWOT terhadap proposisi nilai, biaya dan pendapatan, infrastruktur serta hubungan pelanggan didalam bisnis yang dijalankan Unick Barbershop sekarang ini. Berdasarkan hasil analisis SWOT secara umum dikelompokkan menjadi dua lingkungan utama yaitu:

1) Analisis lingkungan internal berupa kekuatan dan kelemahan

2) Analisis eksternal berupa peluang dan ancaman

\section{Analisis lingkungan internal berupa kekuatan}

\section{dan kelemahan}

Berdasarkan Matriks Internal Factor Analysys (IFAS) yang diperoleh dari penyebaran kuesioner dengan hasil skor bobot untuk faktor kekuatan sebesar 2,38329. Sedangkan total skor faktor kelemahan di peroleh sebesar 0,69476. Hal ini menunjukkan Unick Barbershop Yogyakarta memiliki kekuatan yang lebih besar dibanding kelemahan. Dapat dismpulkan Unick barbershop Yogyakarta dapat lebih mampu mengatasi kelemahan selama ini.
Analisis faktor-faktor ekternal peluang dan ancaman (EFAS).

Berdasarkan Matriks Eksternal Factor Analysys (EFAS) pada usaha Unick Barbershop Yogyakarta nilai skor peluang sebesar 2,25313; sedangkan faktor ancaman 1,52364. Setelah melakukan pembobotan IFAS dan EFAS, maka dilakukan pemberian rating yang kemudian dikalikan dengan bobotnya sehingga didapat score untuk masing-masing faktor. Score yang didapat akan digunakan pemetaan pada diagram SWOT sehingga didapat strategi tepat yang perlu dikembangkan. Berdasarkan hasil perhitungan skor pembobotan, kekuatan, kelemahan, peluang dan ancaman sebagai berikut:

$$
\begin{aligned}
& \text { SW }=2,38329-0,69476=1,6 \\
& \mathrm{OT}=2,25313-1,52346=0,73
\end{aligned}
$$

Berdasarkan hasil perhitungan tersebut, maka usaha Unick Barbershop berada dalam posisi Kuadran I yaitu mendukung strategi agresif.

\section{Hasil dan Pembahasan}

Berikut ditampilkan hasil Tows matrix pada usaha Unick Barbershop sebagaimana berikut ini:

\section{STRATEGI S-O}

- $\quad$ Pemanfaatan lokasi (S1, O1)

- Peningkatan kualitas produk (S2, S6, S9, S15, O7, O4)

- Penggunaan media promosi internet murah (S5, S14, O2, O3, O9, O10)

- Program harga termurah kualitas terbaik (S16, S17, O4, O5)

Pengembangan skill karyawan (S3, S13, O7)

CSR berskala kecil (S7, S13, O1, O4)

Melakukan inovasi bisnis (S11, O5, O6, O8,)

\section{STRATEGI W-O}

Blast social media promotion (W2, W4, W10, O2, O3, O9, O10)

Program pengadaan alat dan bahan secara berkala (W3, W6, W7, O5)

- Menjalin mitra dengan komunitas atau institusi (W5, W8, W9, W11, W13, O4, O11, O12) pengembangan quality control (W14, O8)

\section{STRATEGI S-T}

- $\quad$ Pengembangan quality control (S2, S3, S6, S9, S10, T1, T5, T7, T8)

Progeram harga termurah kualitas terbaik (S4, S16, T3)

Blast social media promotion (S5, T2, T6)

Menjalin mitra dengan komunitas atau institusi (S13, T9) 


\section{STRATEGI W-T}

- Menerapkan sistem shifting dan reward (W9, T8)

\section{Hasil Quantitatif Strategic Planning Matrix (QSPM)}

Penilaian prioritas strategi dilakukan dengan metode matriks QSPM dengan mengalikan bobot pada matriks IFE dan EFE, mengalikannya dengan daya tarik strategi (attractive score) untuk menghasilkan Total Attractive Score (TAS). Jumlah keseluruhan TAS dari masingmasing strategi tersebut menentukan prioritas strategi. Berikut hasil penilaian Quantittif Strategic Planning Matrix (QSPM)

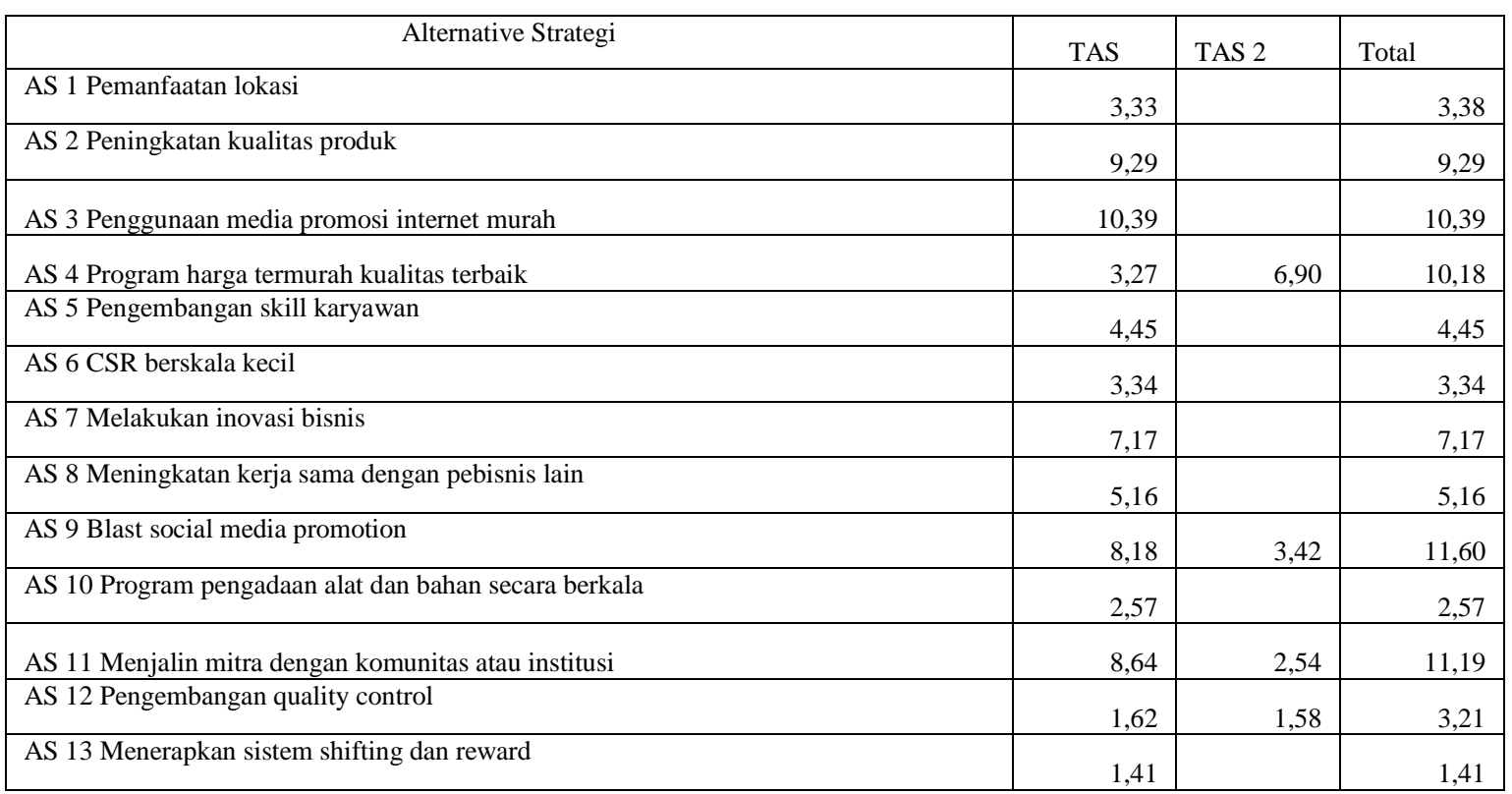

Tabel 1. Total attractive score

Berdasarkan hasil pengolahan matrik QSPM yang dapat disimpulkan yaitu 1) AS9 Blast social media promotion yang memeroleh total attractive score sebesar 11,60. Media promosi dengan system blast disamping murah namun juga efisien karena disebar secara terfokus di suatu daerah yang bisa menarik minat konsumen baru, dan meningkatkan pendapatan. 2) AS11 Menjalin mitra dengan komunitas atau institusi yang memperoleh total attractive score sebesar 11,19. Komunitas dapat menjadi target segmen yang menguntungkan serta menjadi saluran pemasaran untuk memperkenalkan produk. 3). AS3 Penggunaan media promosi internet murah yang memperoleh total attractive score sebesar 10,39. Pemaksimalan promosi menggunakan media social daring agaknya lebih dimaksimalkan agar dapat menarik konsumen dari berbagai segment. 4) AS4 Program harga termurah kualitas terbaik yang memperoleh total attractive score sebesar 10,18. Ancaman eksternal dari faktor competitor lain bisa diminimalisir dengan program memberi harga termurah dari pada di barber lain namun dengan hasil karya yang maksimal.

\section{Pengembangan Bisnis Model Canvas}

Rencana pengembangan model bisnis berkelanjutan Unick Barbershop mengacu pada perubahan yang terjadi pada table alternative strategi. Pengembangan dilakukan dengan menambahkan dan mengurangkan bagian dari setiap elemen sesuai dengan tujuan dan strategi yang akan diterapkan perusahaan. Berikut gambar rancangan pengembangan model bisnis berkelanjutan Unick Barbershop. 


\section{New Canvas Model}

\begin{tabular}{|c|c|c|c|c|}
\hline \multirow[t]{6}{*}{\begin{tabular}{|l|} 
Key Patners (KP) \\
Supllier peralatan \\
potong rambut \\
- PT. Mutiara Mustika \\
- CV. Puspa Indah \\
Onlineshop
\end{tabular}} & $\begin{array}{l}\text { Key Activities }(\text { KA }) \\
\text { Peroses Potong } \\
\text { rambut dari jam } \\
09.00-21.00 . \\
\text { Perawatan potong } \\
\text { rambut. }\end{array}$ & $\begin{array}{l}\text { Value Proposition (VP) } \\
\text { - Memiliki diferensiasi/ } \\
\text { inovasi yang menjadi } \\
\text { daya tarik khas yang kami } \\
\text { yakini mampu menarik } \\
\text { pelanggan }\end{array}$ & \multirow{4}{*}{\begin{tabular}{|l} 
Customer \\
Relationship $($ CR) \\
- Garansi cukur \\
- Ketepatan waktu \\
- Diskon Cukur 3 \\
orang Gratis 1 Orang \\
- Harga terjangkau \\
- Member card \\
- Wifi gratis
\end{tabular}} & \multirow{2}{*}{$\begin{array}{l}\text { Customer Segments } \\
\text { (CS) } \\
\text { - Pria dan anak } \\
\text { - Mahasiswa } \\
\text { - Pelajar } \\
\text { - Warga perumahan } \\
\text { - } \text { sekitar } \\
\text { - Turis internasional } \\
\text { dan lokal }\end{array}$} \\
\hline & \multirow{3}{*}{$\begin{array}{l}\text { Mengurangi } \\
\text { pengunaan silet } \\
\text { sekali pakai, } \\
\text { diganti dengan } \\
\text { Shaver }\end{array}$} & \multirow{2}{*}{$\begin{array}{l}\text { - Menjaga hubungan } \\
\text { emosional dengan } \\
\text { pelanggan, sehigga } \\
\text { menciptakan pelanggan } \\
\text { loyal } \\
\text { - Hairstaylist yang handal } \\
\text { dan harga terjangkau }\end{array}$} & & \\
\hline & & & & \multirow[t]{2}{*}{$\begin{array}{l}\text { - Pemuda } \\
\text { mengangur } \\
\text { - Pemerintah } \\
\text { - Warga sekitar }\end{array}$} \\
\hline & & $\begin{array}{l}\text { - Membuka lapangan kerja } \\
\text { - Kesejahteraan karyawan } \\
\text { - Kerjasama pengelolaan } \\
\text { limbah Rambut } \\
\text { - Hemat Energi } \\
\text { - Hemat Air }\end{array}$ & & \\
\hline & $\begin{array}{l}\text { Key Resources } \\
(\boldsymbol{K R}) \\
\text { SDM Unick } \\
\text { barbershop } \\
\text { Pelanggan }\end{array}$ & \multirow{2}{*}{\multicolumn{3}{|c|}{$\begin{array}{l}\text { Channels }(\boldsymbol{C H}) \\
\text { ick Barbershop } \\
\text { acebook, Whats App,Instagram } \\
\text { mpus,sekolah, dan kantor }\end{array}$}} \\
\hline & $\begin{array}{l}\text { - Update } \\
\text { model rambut }\end{array}$ & & & \\
\hline \multicolumn{2}{|c|}{$\begin{array}{l}\text { Cost Structure (CS) } \\
\text { Data Keuangan: } \\
\text { 1. Investasi awal } \\
\text { 2. Biaya Operasional } \\
\text { 3. Aliran pendapatan uang masuk } \\
\text { 4. Analisis Biaya dan keuntungan }\end{array}$} & \multicolumn{3}{|c|}{$\begin{array}{l}\text { - Margin Keuntungan } \\
\text { - Penjualan produk }\end{array}$} \\
\hline
\end{tabular}

Tabel 2. Bisnis model canvas usulan

\section{Kesimpulan}

1. Posisi Unick Barbershop berada pada kuadran pertama, hal ini menunjukkan bahwa perusahaan berada pada posisi agresif. Strategi ini dibuat dengan menggunakan seluruh kekuatan untuk memanfaatkan peluang yang ada. Strategi yang dapat dilakukan adalah lebih fleksibel dalam persaingan bisnis, lebih fokus dalam pemasaran, memanfaatkan channel maupun mitra bisnis secara maksimal dan mengendalikan secara penuh kinerja pelayanan.

2. Inovasi model bisnis perusahaan dibutuhkan pengambangan di 4 blok model yang terdiri dari customers segment, value proposition, key resource, dan key activities yang dapat meningkatkan kualitas layanan, kompetensi sumber daya manusia, serta menunjang pencapaian jangka panjang perusahaan dengan lebih terukur.

\section{DAFTAR PUSTAKA}

[1]Anna,L.K.,2017.https://lifestyle.kompas.com/rea d/2017/07/13/0833300320/penghasilan-

menjanjikan-dari-bisnis-barbershop.

[2]Rianti,E.,2019.https://lifestyle.bisnis.com/read/2 0190124/220/881907/tren-gaya-rambut-pria2019-bakal-lebih-modern.
[3]Setyanta, B., 2017. Anteseden dan Konsekuensi dari Kepuasan Pelanggan: Survei Kepuasan Pelanggan Barbershop di Yogyakarta. Al Tijarah, Juni, 3(1), 30-44.

[4]Madja, T. K., Tumbuan, W. J. \& Pandowo, M., 2017. Analisa Persepsi Kualitas Dan Persepsi Nilai Menggunakal Analisa Ipa Pada Barbershop Vonnette Di Manado. Jurnal EMBA,5(2), 25082515.

[5]Rezaee, Z., Dou, H. \& Zhang, H., 2019. Corporate Social Responsibility and Earnings Quality: Evidence from China. Global Finance Journal, 4 May.pp. 1-61.

[6]Osterwalder, A. \& Pigneur, Y., 2010. Business Model Generation. s.1.:Patrick van der Pijl. 